\title{
Incidence trends and survival prediction of urothelial cancer of the bladder: a population-based study
}

\author{
Hairong He ${ }^{1,2}$, Tianjie Liư ${ }^{3}$, Didi Han², Chengzhuo Li ${ }^{2}$, Fengshuo Xu², Jun Lyu ${ }^{2,4}$ and Ye Gao ${ }^{5^{*}}$
}

\begin{abstract}
Background: The aim of this study is to determine the incidence trends of urothelial cancer of the bladder (UCB) and to develop a nomogram for predicting the cancer-specific survival (CSS) of postsurgery UCB at a populationbased level based on the SEER database.

Methods: The age-adjusted incidence of UCB diagnosed from 1975 to 2016 was extracted, and its annual percentage change was calculated and joinpoint regression analysis was performed. A nomogram was constructed for predicting the CSS in individual cases based on independent predictors. The predictive performance of the nomogram was evaluated using the consistency index (C-index), net reclassification index (NRI), integrated discrimination improvement (IDI), a calibration plot and the receiver operating characteristics (ROC) curve.

Results: The incidence of UCB showed a trend of first increasing and then decreasing from 1975 to 2016. However, the overall incidence increased over that time period. The age at diagnosis, ethnic group, insurance status, marital status, differentiated grade, AJCC stage, regional lymph nodes removed status, chemotherapy status, and tumor size were independent prognostic factors for postsurgery UCB. The nomogram constructed based on these independent factors performed well, with a C-index of 0.823 and a close fit to the calibration curve. Its prediction ability for CSS of postsurgery UCB is better than that of the existing AJCC system, with NRI and IDI values greater than 0 and ROC curves exhibiting good performance for 3, 5, and 8 years of follow-up.

Conclusions: The nomogram constructed in this study might be suitable for clinical use in improving the clinical predictive accuracy of the long-term survival for postsurgery UCB.
\end{abstract}

Keywords: Urothelial cancer of the bladder, Incidence, Survival, Nomogram

\section{Introduction}

Urothelial cancer of the bladder (UCB) is the most common pathological type of bladder cancer, and its incidence is especially high in Western countries $[1,2]$. The incidence of this cancer is closely related to tobacco consumption and exposure to occupational carcinogens [3, 4]. However, the incidence of UCB may have changed

\footnotetext{
* Correspondence: xiaogaoego@163.com

${ }^{5}$ Department of Emergency, The First Affiliated Hospital of Xi'an Jiaotong University, 277 West Yanta Road, Xi'an, Shaanxi 710061, People's Republic of China

Full list of author information is available at the end of the article
}

over the past few decades due to industrial developments, the implementation of policies for controlling tobacco, and progress in disease diagnosis and treatment $[5,6]$. There have been few analyses of the incidence of UCB despite many studies researching the incidence trends of bladder cancer [7].

UCB is most frequently diagnosed in males and people older than 55 years [7]. Surgical resection is the mainstay treatment for UCB, but many people-especially those presenting with muscle invasion-have poor outcomes despite receiving surgery and systemic treatment [8].

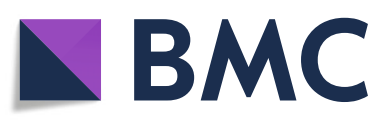

(c) The Author(s). 2021 Open Access This article is licensed under a Creative Commons Attribution 4.0 International License, which permits use, sharing, adaptation, distribution and reproduction in any medium or format, as long as you give appropriate credit to the original author(s) and the source, provide a link to the Creative Commons licence, and indicate if changes were made. The images or other third party material in this article are included in the article's Creative Commons licence, unless indicated otherwise in a credit line to the material. If material is not included in the article's Creative Commons licence and your intended use is not permitted by statutory regulation or exceeds the permitted use, you will need to obtain permission directly from the copyright holder. To view a copy of this licence, visit http://creativecommons.org/licenses/by/4.0/. The Creative Commons Public Domain Dedication waiver (http://creativecommons.org/publicdomain/zero/1.0/) applies to the data made available in this article, unless otherwise stated in a credit line to the data. 
Although prognostic factors for UCB have been reported [9-16], reliable nomograms for individualized predictions of the long-term survival of postsurgery patients with UCB are still lacking.

Given the aforementioned situation, this study analyzed trends in the incidence of UCB and established a nomogram based on a Cox proportional-hazards regression analysis of the prognostic factors for predicting the survival of UCB after surgery based on data obtained from the Surveillance, Epidemiology, and End Results (SEER) database [17].

\section{Methods}

\section{Data collection and definition}

The data were extracted retrospectively from the SEER database and downloaded using SEER*Stat software (version 8.3.6, National Cancer Institute). To identify UCB patients, we searched the database using the tumor-site ICD-9 codes (C67.0-C67.9) and ICD-O-3 code (8130/3). To analyze the trends in the incidence of UCB, the ageadjusted incidence rate of UCB diagnosed from 1975 to 2016 was calculated.

To establish a nomogram for analyzing survival, the following variables for UCB were extracted from the SEER database: age at diagnosis, sex, ethnic group, primary site, grade, metastasis stage, derived AJCC stage, regional lymph nodes removed, radiation status, chemotherapy status, insurance status, marital status, tumor size, survival time, and cancer-specific death status. We only included patients who received surgery, which were identified with "Surgery performed" record on the item "Reason no cancer-directed surgery." Other exclusion criteria were (1) only autopsy findings being available, (2) diagnosis based on direct visualization without microscopic confirmation, (3) not the first malignant primary indicator, and (4) incomplete information for the above-listed variables.

\section{Statistical analyses}

The data for the age-adjusted incidence rate of UCB from 1975 to 2016 was used to calculate the annual percentage change (APC) in the incidence using the weighted least-squares method. Joinpoint regression analysis (version 4.7.0, Joinpoint, IMS, Calverton, MD, USA) was performed to delineate trends in the incidence of UCB from 1975 to 2016. Considering the large difference in the incidence between males and females, the APC analysis and the joinpoint regression analysis were performed with stratification by sex.

All of the patients included in the cancer-specific survival (CSS) analysis were randomly divided into a training cohort and a validation cohort at the ratio of 7:3. We first used the data in the training set to find independent prognostic factors and construct a nomogram, and then applied the data to the validation cohort to evaluate the distinguishability, calibration, and clinical effectiveness of the prediction model.

Differences in the distribution of categorical variables between the training cohort and validation cohort were estimated using the chi-square test. Differences in age between the two cohorts were assessed using Student's $t$ test, and differences in survival time were assessed using the log-rank test. Statistical analyses to identify risk factors were performed by applying the backward stepwise selection method of multivariable Cox regression to the training cohort. A nomogram was then established based on the identified risk factors.

The distinguishability of the nomogram was evaluated using the consistency index (C-index) calculated by Harrell's $\mathrm{C}$ statistic, the net reclassification index (NRI), and the integrated discrimination improvement (IDI). The $\mathrm{C}$-index was used to describe the difference between the real values and those predicted by the model. This index ranges from 0.5 (no discrimination) to 1 (excellent discrimination), with a value of $\geq 0.70$ indicating that the distinguishability of the prediction model is acceptable. Values of NRI and IDI of $>0$ (compared with the traditional AJCC staging system) indicate that the prediction ability of the nomogram is better than that of the AJCC staging system, while negative values would indicate that it is inferior.

The calibration of the nomogram was evaluated using a calibration plot, on which the abscissa shows the predicted values for different groups and the ordinate shows the actual probabilities. The value points for different groups are connected by line segments to form a calibration line. A calibration curve that is closer to the standard line of $y=x$ indicates a smaller error between the model's prediction and the actual situation, and hence a better calibration capability of the model. The clinical effectiveness of the nomogram was evaluated using the receiver operating characteristics (ROC) curve.

Statistical analyses were performed using the $\mathrm{R}$ software (version 3.5.1; https://www.r-project.org/). Statistical significance was defined as a two-sided probability value of $<0.05$.

\section{Results}

\section{Incidence trends}

The age-adjusted incidence rate of UCB increased from 8.4 per 100,000 persons in 1975 to 13.1 per 100,000 persons in 2016. The joinpoint regression analysis revealed there were two join points (Fig. 1). The incidence rate showed a rapidly increasing trend from 1975 to 1987, with an APC of 3.3\% (95\% confidence interval $[\mathrm{CI}]=$ 2.8-3.9\%, $P<0.0001$ ), while this increase slowed from 1988 to 2001 ( $\mathrm{APC}=0.8 \%, 95 \% \mathrm{CI}=0.4-1.1 \%, P<$ 0.0001 ), and was followed by a decreasing trend from 

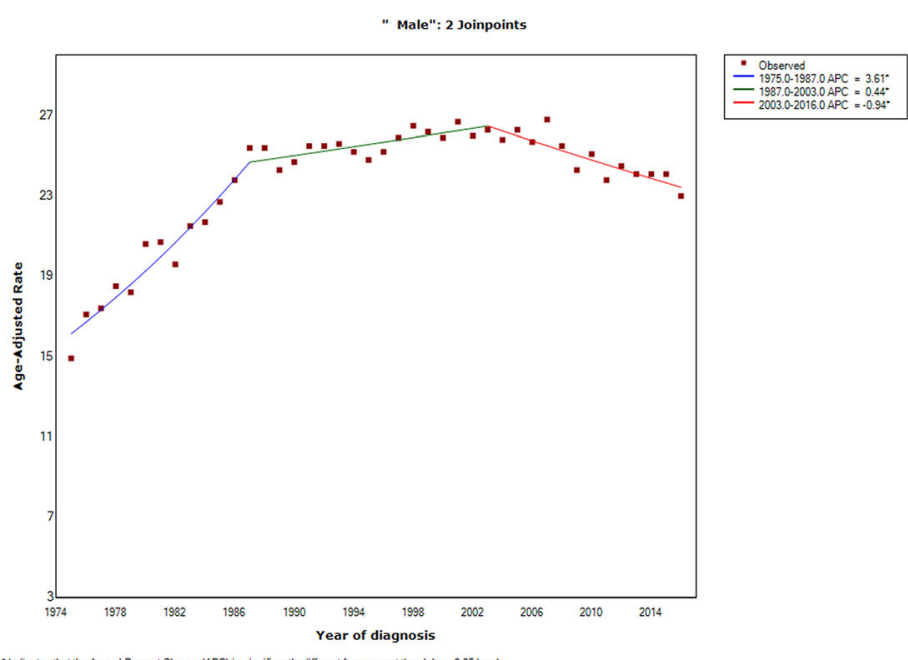

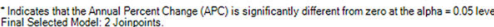

Male and female: 2 Joinpoints
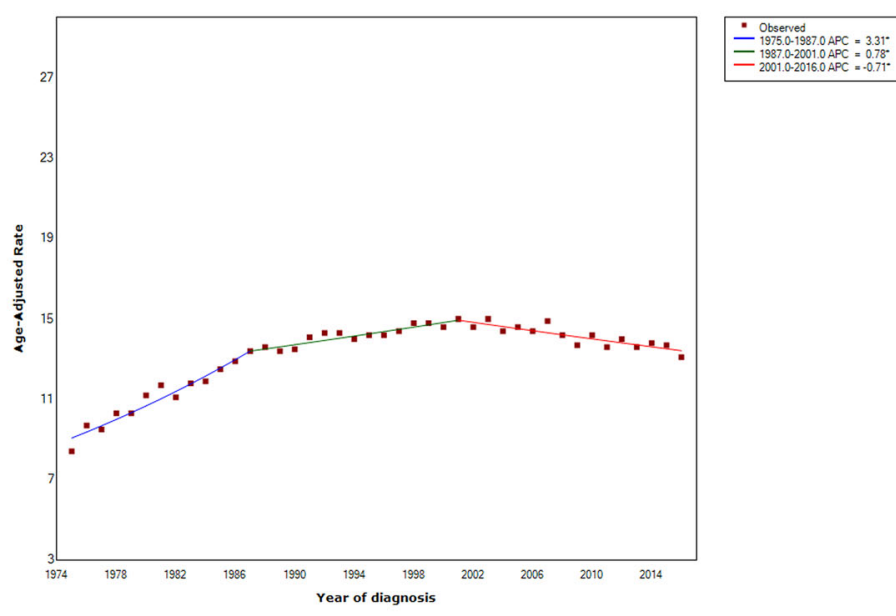

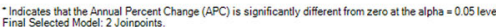

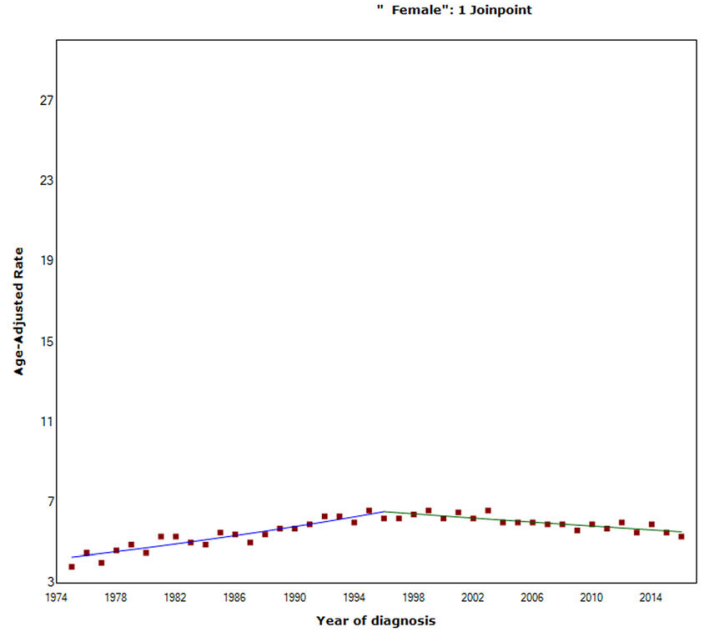

Fig. 1 The incidence trends by sex of urothelial cancer of the bladder from 1975 to 2016 
Table 1 Baseline characteristic of the patients with urothelial cancer of the bladder

\begin{tabular}{|c|c|c|c|c|c|c|c|}
\hline Factors & $\begin{array}{l}\text { Training cohort } \\
(n=8058)\end{array}$ & $\%$ & $\begin{array}{l}\text { Validation cohort } \\
(n=3454)\end{array}$ & $\%$ & Total $(n=11512)$ & $\%$ & $P$ \\
\hline$\overline{\text { Age }^{1}}$ & $70.20 \pm 11.61$ & & $70.68 \pm 11.92$ & & $70.35 \pm 11.71$ & & 0.04 \\
\hline Sex & & & & & & & 0.07 \\
\hline Male & 6322 & 78.46 & 2658 & 76.95 & 8980 & 78.01 & \\
\hline Female & 1736 & 21.54 & 796 & 23.05 & 2532 & 21.99 & \\
\hline Grade & & & & & & & 0.99 \\
\hline Well & 309 & 3.83 & 134 & 3.88 & 443 & 3.85 & \\
\hline Moderately & 1059 & 13.14 & 455 & 13.17 & 1514 & 13.15 & \\
\hline Poorly & 1735 & 21.53 & 738 & 21.37 & 2473 & 21.48 & \\
\hline Undifferentiated & 4955 & 61.49 & 2127 & 61.58 & 7082 & 61.52 & \\
\hline Ethnic group & & & & & & & 0.97 \\
\hline White & 7171 & 88.99 & 3069 & 88.85 & 10240 & 88.95 & \\
\hline Black & 458 & 5.68 & 198 & 5.73 & 656 & 5.70 & \\
\hline Other & 429 & 5.32 & 187 & 5.41 & 616 & 5.35 & \\
\hline Marital status & & & & & & & 0.06 \\
\hline Married & 5098 & 63.27 & 2111 & 61.12 & 7209 & 62.62 & \\
\hline Single & 1025 & 12.72 & 446 & 12.91 & 1471 & 12.78 & \\
\hline SDW & 1935 & 24.01 & 897 & 25.97 & 2832 & 24.60 & \\
\hline Insurance & & & & & & & 0.41 \\
\hline Yes & 7789 & 96.66 & 3349 & 96.96 & 11138 & 96.75 & \\
\hline No & 269 & 3.34 & 105 & 3.04 & 374 & 3.25 & \\
\hline Location & & & & & & & 0.19 \\
\hline Urachus/dome & 303 & 3.76 & 140 & 4.05 & 443 & 3.85 & \\
\hline Trigone, neck, ureteric orifice & 951 & 11.80 & 365 & 10.57 & 1316 & 11.43 & \\
\hline Wall & 2920 & 36.24 & 1294 & 37.46 & 4214 & 36.61 & \\
\hline NOS/overlap & 3884 & 48.20 & 1655 & 47.92 & 5539 & 48.12 & \\
\hline Stage & & & & & & & 0.82 \\
\hline Localized & 6782 & 84.16 & 2906 & 84.13 & 9688 & 84.16 & \\
\hline Regional & 953 & 11.83 & 417 & 12.07 & 1370 & 11.90 & \\
\hline Distant & 323 & 4.01 & 131 & 3.79 & 454 & 3.94 & \\
\hline AJCC & & & & & & & 0.41 \\
\hline । & 5214 & 64.71 & 2247 & 65.06 & 7461 & 64.81 & \\
\hline$\|$ & 1627 & 20.19 & 685 & 19.83 & 2312 & 20.08 & \\
\hline III & 499 & 6.19 & 236 & 6.83 & 735 & 6.38 & \\
\hline IV & 718 & 8.91 & 286 & 8.28 & 1004 & 8.72 & \\
\hline Size & & & & & & & 0.26 \\
\hline $1-20 \mathrm{~mm}$ & 1647 & 20.44 & 746 & 21.60 & 2393 & 20.79 & \\
\hline $21-49 \mathrm{~mm}$ & 3650 & 45.30 & 1516 & 43.89 & 5166 & 44.87 & \\
\hline$\geq 50 \mathrm{~mm}$ & 2761 & 34.26 & 1192 & 34.51 & 3953 & 34.34 & \\
\hline Regional lymph nodes removed & & & & & & & 0.22 \\
\hline Yes & 1574 & 19.53 & 641 & 18.56 & 2215 & 19.24 & \\
\hline No & 6484 & 80.47 & 2813 & 81.44 & 9297 & 80.76 & \\
\hline
\end{tabular}


Table 1 Baseline characteristic of the patients with urothelial cancer of the bladder (Continued)

\begin{tabular}{|c|c|c|c|c|c|c|c|}
\hline Factors & $\begin{array}{l}\text { Training cohort } \\
(n=8058)\end{array}$ & $\%$ & $\begin{array}{l}\text { Validation cohort } \\
(n=3454)\end{array}$ & $\%$ & Total $(n=11512)$ & $\%$ & $P$ \\
\hline Chemotherapy & & & & & & & 0.45 \\
\hline Yes & 2652 & 32.91 & 1162 & 33.64 & 3814 & 33.13 & \\
\hline No & 5406 & 67.09 & 2292 & 66.36 & 7698 & 66.87 & \\
\hline Radiation & & & & & & & 0.42 \\
\hline Yes & 493 & 6.12 & 225 & 6.51 & 718 & 6.24 & \\
\hline No & 7565 & 93.88 & 3229 & 93.49 & 10794 & 93.76 & \\
\hline
\end{tabular}

SDW separated or divorced or widowed, AJCC American Joint Committee on Cancer

${ }^{1}$ The age was showed as mean \pm standard deviation

2002 to $2016(\mathrm{APC}=-0.7 \%, 95 \% \mathrm{CI}=-0.9 \%$ to $-0.5 \%, P$ $<0.0001)$.

Among male UCB patients, the age-adjusted incidence rate increased from 14.9 per 100,000 persons in 1975 to 23 per 100,000 persons in 2016. The joinpoint regression analysis similarly revealed two join points, as for the total population (Fig. 1). The incidence rate in males showed a rapidly increasing trend from 1975 to 1987 (APC $=3.6 \%, 95 \% \mathrm{CI}=3.0-4.2 \%, P<0.0001)$, which slowed markedly from 1988 to 2003 (APC $=0.4 \%, 95 \% \mathrm{CI}$ $=0.1-0.7 \%, P<0.0001)$, before decreasing from 2004 to $2016(\mathrm{APC}=-0.9 \%, 95 \% \mathrm{CI}=-1.3 \%$ to $-0.6 \%, P<$ $0.0001)$.

Among female UCB patients, the age-adjusted incidence rate increased slightly from 3.8 per 100,000 persons in 1975 to 5.3 per 100,000 persons in 2016. Only one join point was identified (Fig. 1), with the incidence rate showing a slowly increasing trend from 1975 to $1996(\mathrm{APC}=2.0 \%, 95 \% \mathrm{CI}=1.7-2.4 \%, P<0.0001)$, followed by a slowing decreasing trend from 1997 to $2016(\mathrm{APC}=-0.8 \%, 95 \% \mathrm{CI}=-1.2 \%$ to $-0.5 \%, P<$ $0.0001)$.

\section{Characteristic of patients in predictive model}

This study included 11,512 postsurgery UCB patients, with 8058 allocated to the training cohort and 3454 to the validation cohort. The median follow-up time was 37 months (range 1-119 months). Overall, 2607 (22.65.0\%) patients died of postsurgery UCB during the follow-up. The basic characteristic of the patients are listed in Table 1. The total cohort was aged $70.35 \pm$ 11.71 years, and included $8980(78.01 \%)$ male patients. There were 10,240 (88.95\%) white patients, 656 (5.70\%) black patients, and 616 (5.35\%) patients of other ethnic groups. The marital status was divided into 7209 (62.62\%) married patients, 1471 (12.78\%) unmarried or domestic partner or single patients, and 2832 (24.60\%) separated or divorced or widowed patients. There were 11,138 (96.75\%) insured and 374 (3.25\%) uninsured patients. The primary tumor site in the largest proportion
Table 2 The independent prognostic factors by multivariable Cox regression with the backward stepwise selection method in the training cohort

\begin{tabular}{|c|c|c|c|}
\hline Factors & Hazard ratio & $95 \% \mathrm{Cl}$ & $P$ \\
\hline Age & 1.03 & $1.03-1.04$ & $<0.0001$ \\
\hline \multicolumn{4}{|l|}{ Grade } \\
\hline Well & 1 & - & - \\
\hline Moderately & 1.84 & $1.12-3.02$ & 0.016 \\
\hline Poorly & 3.19 & $1.99-5.12$ & $<0.0001$ \\
\hline Undifferentiated & 3.15 & $1.97-5.03$ & $<0.0001$ \\
\hline \multicolumn{4}{|l|}{ Ethnic group } \\
\hline White & 1 & - & - \\
\hline Black & 1.21 & $1.01-1.46$ & 0.043 \\
\hline Other & 0.85 & $0.69-1.06$ & 0.146 \\
\hline \multicolumn{4}{|l|}{ Marital status } \\
\hline Married & 1 & - & - \\
\hline Single & 1.29 & $1.12-1.49$ & 0.0004 \\
\hline $\mathrm{SDW}^{2}$ & 1.22 & $1.1-1.36$ & 0.0002 \\
\hline \multicolumn{4}{|l|}{ Insurance } \\
\hline Yes & 1 & - & - \\
\hline No & 1.39 & $1.09-1.76$ & 0.007 \\
\hline \multicolumn{4}{|l|}{ AJCC } \\
\hline 1 & 1 & - & - \\
\hline$\|$ & 3.59 & $3.17-4.07$ & $<0.0001$ \\
\hline III & 6.8 & $5.74-8.07$ & $<0.0001$ \\
\hline IV & 18.04 & $15.6-20.86$ & $<0.0001$ \\
\hline \multicolumn{4}{|l|}{ Size } \\
\hline $1-20 \mathrm{~mm}$ & 1 & - & - \\
\hline $21-49 \mathrm{~mm}$ & 1.19 & $1.03-1.37$ & 0.021 \\
\hline$\geq 50 \mathrm{~mm}$ & 1.52 & $1.31-1.75$ & $<0.0001$ \\
\hline \multicolumn{4}{|c|}{ Regional lymph nodes removed } \\
\hline Yes & 1 & - & - \\
\hline No & 1.99 & $1.76-2.24$ & $<0.0001$ \\
\hline \multicolumn{4}{|l|}{ Chemotherapy } \\
\hline Yes & 1 & - & - \\
\hline No & 1.41 & $1.27-1.56$ & $<0.0001$ \\
\hline
\end{tabular}


of patients was the anterior, posterior, and lateral walls ( $n=4212,36.61 \%)$, with overlapping lesions/location NOS in 5539 (48.12\%) patients. Most of patients had an undifferentiated grade $(n=7082,61.52 \%)$ or poorly differentiated grade $(n=2473,21.48 \%)$, had a localized metastasis stage $(n=9,688,84.16 \%)$, and were at AJCC stage I ( $n=7461,64.81 \%)$ or II $(n=2312,20.08 \%)$.

In terms of treatment modalities, the regional lymph nodes were removed in 2215 (19.24\%) patients, 3814 (33.13\%) had received chemotherapy, and 718 (6.24\%) had received radiation. There were no significant differences between the training and validation cohorts in sex, ethnic group, tumor size, marital status, insurance status, differentiate grade, metastasis stage, AJCC stage, tumor location, regional lymph nodes removal status, chemotherapy status, or radiation status $(P>0.05)$. The patients in the validation cohort were slightly older than those in the training cohort $(P=0.04)$. The log-rank test showed that the survival time did not differ significantly between the training and validation cohorts $(P=0.3)$.

\section{Independent prognostic factors and construction of the nomogram}

Multivariable Cox regression with the backward stepwise selection method revealed that the statistically significant factors affecting postsurgery UCB survival in the training cohort were the age at diagnosis (hazard ratio $[\mathrm{HR}]=$ $1.03,95 \%$ confidence interval $[\mathrm{CI}]=1.03-1.04$ ), black ethnic group (versus white: $\mathrm{HR}=1.22,95 \% \mathrm{CI}=1.01-$ 1.47), moderately differentiated grade (versus welldifferentiated grade: $\mathrm{HR}=1.82,95 \% \mathrm{CI}=1.11-2.99$ ), poorly differentiated grade (versus well-differentiated grade: $\mathrm{HR}=3.21,95 \% \mathrm{CI}=2.00-5.15)$, undifferentiated grade (versus well-differentiated grade: $\mathrm{HR}=$ 3.13, 95\% CI $=1.96-5.00$ ), AJCC stage II (versus AJCC stage I: $\mathrm{HR}=3.49,95 \% \mathrm{CI}=3.08-3.96)$, AJCC stage III (versus AJCC stage I: $\mathrm{HR}=5.92,95 \% \mathrm{CI}=$ 3.39-10.33), AJCC stage IV (versus AJCC stage I: HR $=12.97,95 \% \mathrm{CI}=7.39-22.75)$, no regional lymph nodes removed (versus regional lymph nodes removed: $\mathrm{HR}=1.82,95 \% \mathrm{CI}=1.60-2.07)$, no chemotherapy (versus received chemotherapy: $\mathrm{HR}=1.41$, 95\% CI $=1.27-1.57$ ), no insurance (versus insured: $\mathrm{HR}=1.40,95 \% \mathrm{CI}=1.10-1.78)$, being single or unmarried or domestic partner (versus married, HR = 1.30, $95 \% \mathrm{CI}=1.13-1.50)$, being separated or divorced or widowed (versus married: $\mathrm{HR}=1.22$, $95 \%$ $\mathrm{CI}=1.10-1.36$ ), tumor size of $21-49 \mathrm{~mm}$ (versus $1-$ $20 \mathrm{~mm}: \mathrm{HR}=1.18,95 \% \mathrm{CI}=1.02-1.36)$, and tumor size of $\geq 50 \mathrm{~mm}$ (versus $1-20 \mathrm{~mm}: \mathrm{HR}=1.48,95 \% \mathrm{CI}=$ 1.28-1.71) (Table 2). These independent prognostic factors were used to construct a prognostic nomogram for predicting the 3-, 5-, and 8-year CSS of postsurgical patients with UCB (Fig. 2). The nomogram shows that the age at diagnosis and the AJCC stage were the strongest factors influencing the prognosis.

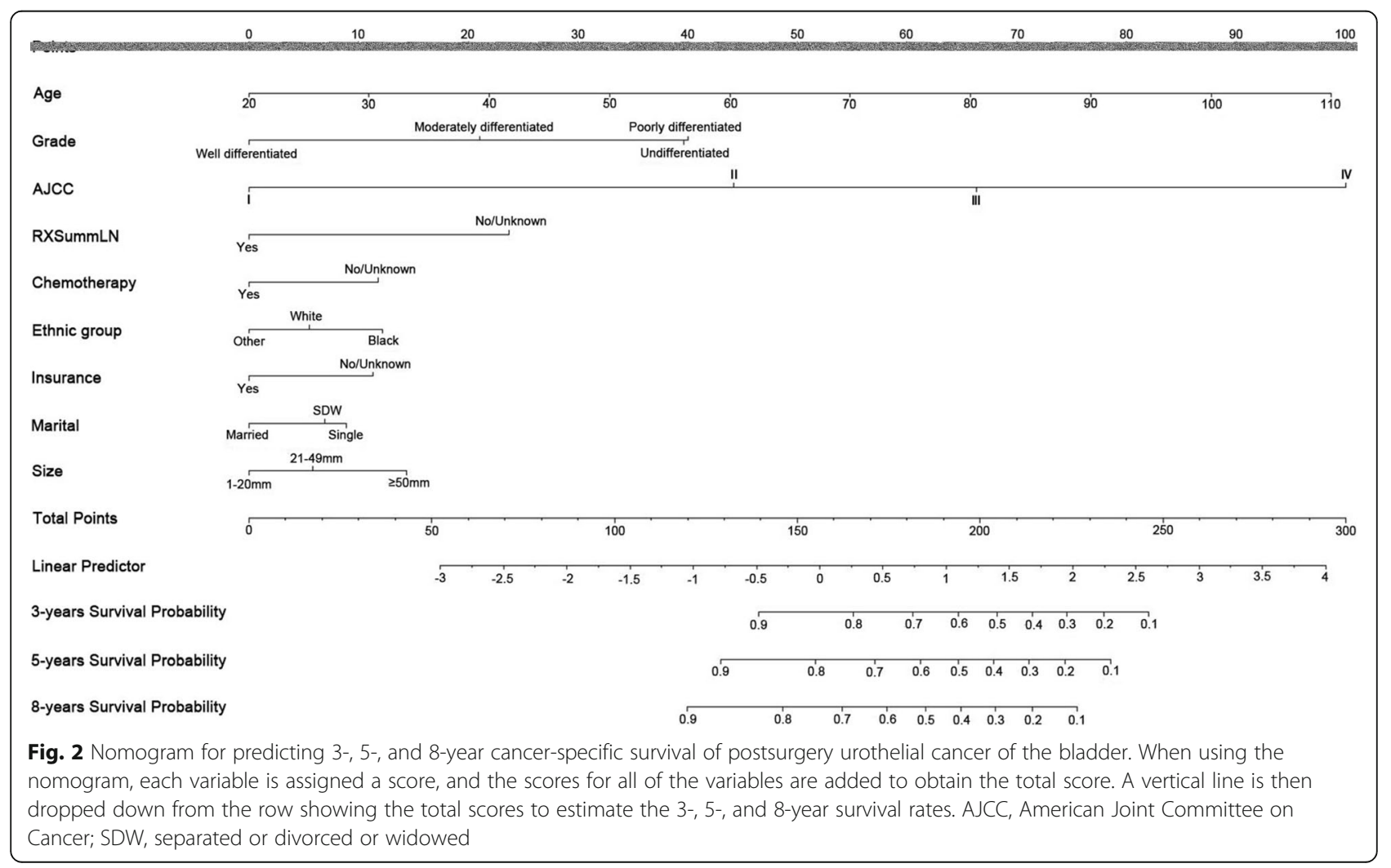




\section{Validation of the nomogram}

The C-index values of the nomogram were 0.820 and 0.823 in the training and verification cohorts, respectively, while those for the AJCC staging system were 0.773 and 0.786. Compared with the AJCC stage, the NRI values for 3,5 , and 8 years of follow-up were 0.34 (95\% CI $=0.28-0.41), 0.37(95 \% \mathrm{CI}=0.33-0.43)$, and 0.39 (95\% CI $=0.34-0.44)$, respectively, in the training cohort, and $0.30(95 \% \mathrm{CI}=0.20-0.40), 0.33(95 \% \mathrm{CI}=$ $0.21-0.41)$, and $0.32(95 \% \mathrm{CI}=0.21-0.42)$ in the validation cohort; the corresponding IDI values were 0.057 , 0.059 , and 0.059 in the training cohort, and 0.042, 0.051, and 0.053 in the validation cohort (all $P<0.001$ ). These performance indicators demonstrate that the nomogram showed better discrimination than the AJCC staging system.
The calibration plots showed excellent consistency between the observed and nomogram-predicted probabilities in the training and validation cohorts (Fig. 3). The ROC curve of the predictive model showed good clinical effectiveness in both the training cohort (Fig. 4A), with areas under the ROC curve (AUCs) for 3, 5, and 8 years of follow-up of $0.831,0.808$, and 0.789 , respectively, and the validation cohort (Fig. 4B), with corresponding AUCs of 0.811, 0.798, and 0.789.

\section{Discussion}

This study analyzed incidence trends in order to establish a survival predictive model for postsurgery UCB based on data in the SEER database. From 1975 to 2016, the overall incidence rate showed an upward trend, despite a slight decrease from the beginning of the twenty-

\section{A}

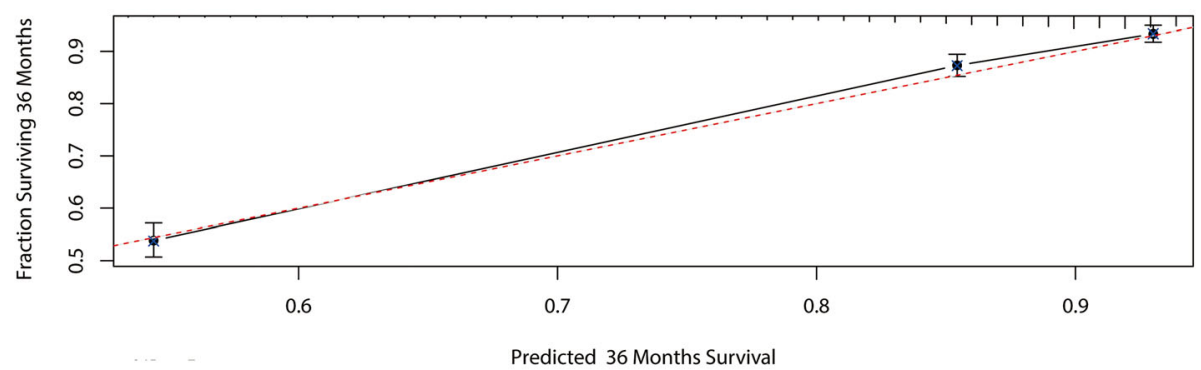

B

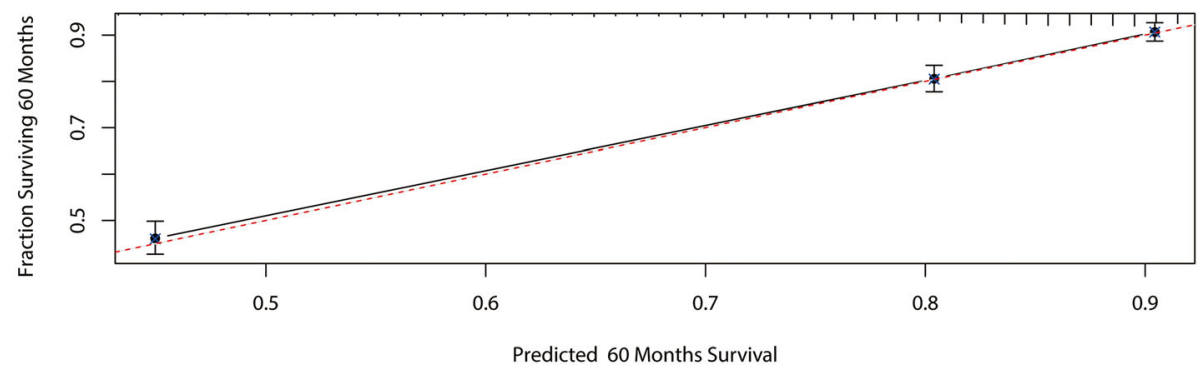

C

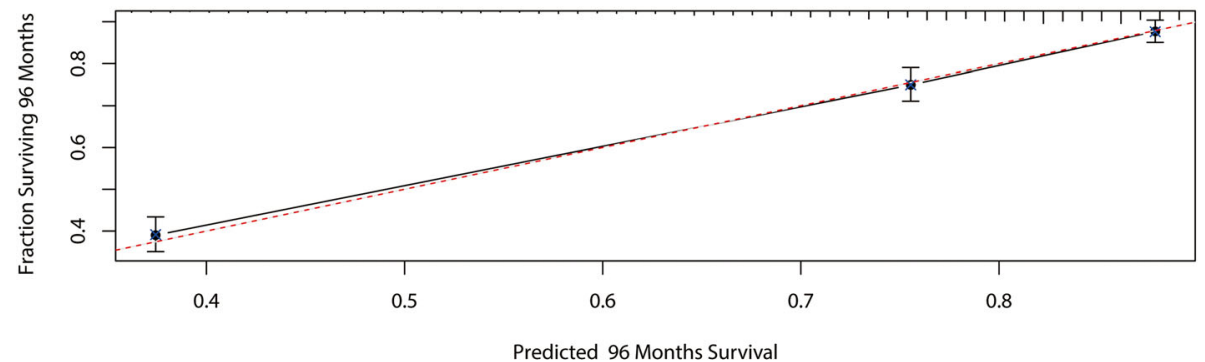

Fig. 3 Calibration curves for 3- (A), 5- (B), and 8-year (C) cancer-specific survival of postsurgery urothelial cancer of the bladder in the validation cohort. X-axis, predicted survival probabilities by the nomogram. Y-axis, actual fraction surviving 
A

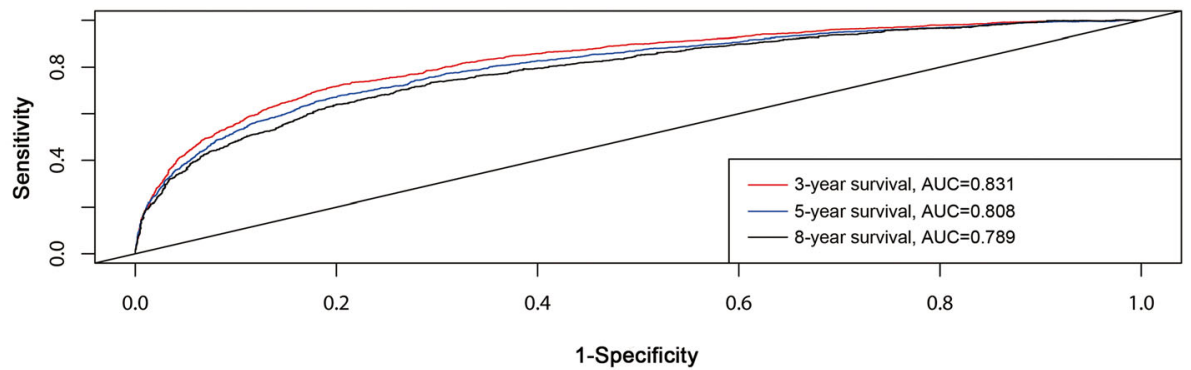

B

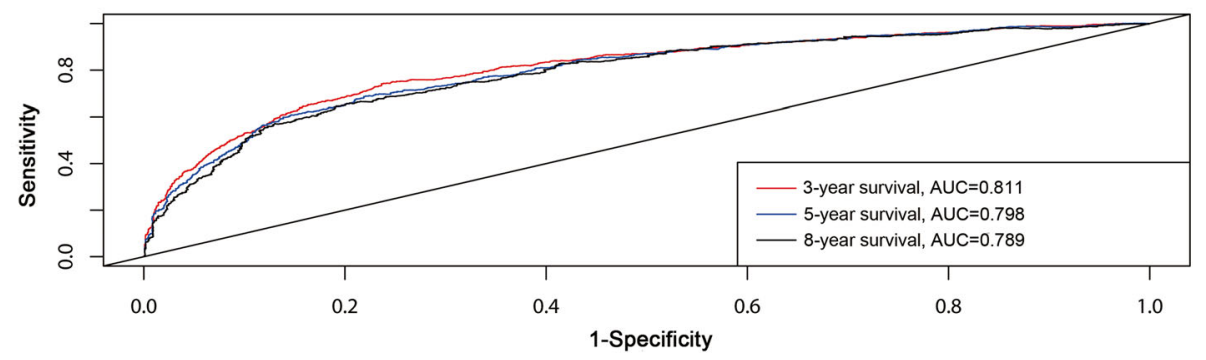

Fig. 4 3-, 5-, and 8-year ROC curves in training (A) and validation cohorts (B) for validating nomogram model. ROC curve analyses were generated to test the performance evaluating of the new nomogram, by the areas under the ROC curves (AUC)

first century. Although management methods for UCB have evolved over the past 30 years, there has been no model for predicting the individualized CSS for UCB. The nomogram established in this study provides very accurate individualized prognostic predictions for postsurgery UCB patients, with good distinguishability and calibration.

The overall upward trend in the incidence of UCB over the past 40 years is consistent with the results of many studies, although the types of pathologies investigated have varied [18-22]. This increase is mostly attributable to progress in the development of diagnostic tools, especially in ultrasonography, computed tomography, and magnetic resonance imaging [23]. Another possible reason is the global trend of population aging, since this cancer is more common in the elderly, while the joinpoint regression also found that the incidence of UCB was not always rising, but had experienced a process of rapid rise, slow rise and then decline in men and the general population. We speculate the downward trend may be related to the control of tobacco consumption. Tobacco smoking is the main factor underlying the incidence of bladder cancer [24]. A report from the Centers for Disease Control and Prevention showed that the smoking rate has decreased markedly in American adults over the past few decades, from $42.4 \%$ in 1965 to $16.8 \%$ in 2014 [18]. It should be noted that there was long latency between tobacco exposition and bladder cancer diagnosis [25]. So the downward trend only began to appear around 2000. Another issue is that the incidence of female UCB had declined in earlier years. We suspect that the possible explanation is that women had a lower bladder cancer incidence because of potential biologic factors, and the decrease in tobacco consumption exerted a more significant impact on them.

Our study found that the prognosis is worse for postsurgery UCB patients who are single, separated, divorced, or widowed than it is for married patients. We speculate that this could be due to the mental status of UCB patients affecting their survival. It has been shown that single patients with bladder cancer are more likely to have a posttreatment psychiatric diagnosis than are married patients, and that the prognosis of bladder cancer is worse in patients with a psychiatric diagnosis [26]. Other analyses of the prognosis of bladder cancer using data from the SEER database have also found that the marital status can affect the prognosis of the disease [27, 28].

We further found that the prognosis is worse in patients without insurance than in those receiving medical insurance/medical assistance. This is somewhat consistent with the findings of Sung et al. [29] based on California Cancer Registry data that the survival time for bladder cancer is worse for not-insured patients and those with an unknown insurance status than it is for those with managed care, although there was no significant difference in the CSS. That study also found that among all insurance categories, the prognosis was worst for Medicaid insurance in the USA. We speculate that the main reason is that Medicaid is aimed at low-income people, who are less likely to receive treatment within 12 
weeks of a diagnosis [30]. Sung et al. [29] also found that Medicaid patients had more advanced-stage, highergrade tumors compared with patients covered by Medicare or managed care, and so their prognosis may be worse. This has been confirmed in other previous research [31]. In our study, we did not subdivide the patients into different types of insurance, instead only dividing them into insured and uninsured/unknown, which may be the main reason for the difference in the research results. Regardless, the type of and accessibility to medical insurance may affect the survival rate of bladder cancer, possibly due to differences in basic living conditions (e.g., income and living environment), disease prevention, and the treatment of people covered by different types of medical insurance.

Other independent prognostic factors for postsurgery UCB identified in this study were the age at diagnosis, black ethnic group, lower differentiation grade, lower AJCC stage, no regional lymph nodes removed, not receiving chemotherapy, and larger tumor, which is traditional prognostic factors for bladder cancer that have been reported previously [32-34]. Based on these factors and the aforementioned marital status and insurance status, we established a nomogram for the individualized prognosis of postsurgery UCB, and found that the AJCC stage and the age had the greatest impact on individualized prognoses. This was not surprising. The AJCC stage itself reflected the severity of the tumor to a large extent. On the other hand, the elderly patients usually suffered from reduced physiological function, coupling with other underlying diseases, resulting in that perioperative mortality and postoperative complications had increased significantly. Additionally, the risk of recurrence increased with age, and the prognosis of older patients was poor [35]. However, the contribution of other variables to the model cannot be ignored. We calculated the NRI and IDI of established model using "Age + AJCC stage" as the control model and found the NRI values for 3,5 , and 8 years of follow-up were $0.23,0.2$, and 0.17 , respectively, in the training cohort, and $0.19,0.12$, and 0.12 in the validation cohort; the corresponding IDI values were $0.03,0.03$, and 0.03 in the training cohort, and $0.02,0.02$, and 0.03 in the validation cohort (all $P<$ 0.001). These indicated that variables other than AJCC and age also exerted a positive contribution to the prediction of prognosis.

The nomogram developed in this study is the first one reported for postsurgery UCB. Zhang et al. [36] established a nomogram for the individualized prognosis of bladder cancer based on data in the SEER database. The variables in that model include the age at diagnosis, ethnic group, sex, and TNM stage. That model also indicated that age and the $\mathrm{T}$ stage have the greatest impact on the prognosis, which is essentially consistent with our model; the main differences are that we used AJCC staging, which is also based on the TNM stage, and we targeted postsurgery UCB. Our nomogram might be superior since we take into account the clinical treatment received by the patients and a broader range of demographic information. In addition, the nomogram that we have established exhibits good discrimination, calibration, and clinical effectiveness, and a better prognostic ability for postsurgery UCB than the currently used AJCC staging system. This easy-to-use nomogram can help doctors to estimate the likelihood that a patient will survive at a certain point in time.

Several limitations of this study should be considered. Firstly, the data used in the validation cohort also came from the SEER database, and so the nomogram still needs to be validated using data from another database or using clinical prospective data. Secondly, some important clinical factors were not collected, such as the smoking status after diagnosis, parameters of social status (e.g., socioeconomic status or level of education), condition of the underlying disease, comorbidities, and biochemical indicators such as the C-reactive protein level. The data available are also subject to the limitations of the SEER database. Finally, for patients with bladder cancer to have a good prognosis, preventing relapse is also an important indicator for the clinical treatment of the disease $[37,38]$, but we did not analyze the risk of recurrence in patients.

\section{Conclusions}

In conclusion, this study has revealed the incidence trends of UCB and constructed a nomogram for predicting the long-term survival of individual postsurgery UCB patients based on a population cohort. The nomogram showed good predictive performance, and may serve as an effective and convenient evaluation tool for helping surgeons to perform personalized survival predictions and mortality risk identification in postsurgery UCB patients.

\section{Abbreviations \\ UCB: Urothelial cancer of the bladder; AJCC: American Joint Committee on Cancer; CSS: Cancer-specific survival; NRI: Net reclassification index; IDI: Integrated discrimination improvement; APC: Annual percentage change; ROC: Receiver operating characteristics; AUC: Areas under the ROC curve; HR: Hazard ratio; Cl: Confidence interval}

\section{Acknowledgements \\ Thanks to the SEER Program tumor registries for providing high-quality open resources.}

\section{Authors' contributions}

Study design: $Y G, J L$, and HH. Data collection: $H H, D H$, and $C L$. Data analyses: $\mathrm{HH}, \mathrm{FX}$, and TL. Results interpretations: All authors. Manuscript writing: $\mathrm{HH}$ and TL. Manuscript proofing: YG and $\mathrm{HH}$. All authors have read and approved the manuscript. 


\section{Funding}

This study was supported by the National Social Science Foundation of China (No.16BGL183) and the Key Research and Development Program of Shaanxi Province, China (No.2019SF-140). The funders had no role in the study design, collection, analysis, interpretation, or writing of the manuscript.

\section{Availability of data and materials}

The data that support the findings of this study are available on request from the corresponding author.

\section{Declarations}

\section{Ethics approval and consent to participate}

Not applicable. SEER is a publically available anonymous data source, so this study was not reviewed by a Human Subjects Committee.

\section{Consent for publication}

Not applicable.

\section{Competing interests}

The authors declare that they have no competing interests.

\section{Author details}

${ }^{1}$ Clinical Research Center, The First Affiliated Hospital of Xi'an Jiaotong University, Xi'an, Shaanxi, People's Republic of China. ${ }^{2}$ School of Public Health, Xi'an Jiaotong University Health Science Center, Xi'an, Shaanxi, People's Republic of China. ${ }^{3}$ Department of Urology, The First Affiliated Hospital of Xi'an Jiaotong University, Xi'an, Shaanxi, People's Republic of China. ${ }^{4}$ Department of Clinical Research, The First Affiliated Hospital of Jinan University, Guangzhou, People's Republic of China. ${ }^{5}$ Department of Emergency, The First Affiliated Hospital of Xi'an Jiaotong University, 277 West Yanta Road, Xi'an, Shaanxi 710061, People's Republic of China.

Received: 16 May 2021 Accepted: 3 July 2021

Published online: 26 July 2021

\section{References}

1. Richters A, Aben K, Kiemeney L. The global burden of urinary bladder cancer: an update. World J Urol. 2020;38(8):1895-904. https://doi.org/10.1 007/s00345-019-02984-4

2. Piszczek R, Nowak L, Krajewski W, Chorbinska J, Poletajew S, Moschini M, et al. Oncological outcomes of laparoscopic versus open nephroureterectomy for the treatment of upper tract urothelial carcinoma: an updated meta-analysis. World J Surg Oncol. 2021;19(1):129. https://doi. org/10.1186/s12957-021-02236-z.

3. Chavan S, Bray F, Lortet-Tieulent J, Goodman M, Jemal A. International variations in bladder cancer incidence and mortality. Eur Urol. 2014;66(1): 59-73. https://doi.org/10.1016/j.eururo.2013.10.001.

4. Xu S, Zhang GM, Guan FJ, Dong DH, Luo L, Li B, et al. The association between metabolic syndrome and the risk of urothelial carcinoma of the bladder: a case-control study in China. World J Surg Oncol. 2015;13(1):236. https://doi.org/10.1186/s12957-015-0631-5.

5. DeGeorge KC, Holt HR, Hodges SC. Bladder cancer: diagnosis and treatment Am Fam Physician. 2017;96(8):507-14.

6. Yao L, Yang K, Li X, Zhang Z, Zhang C, Gong K, et al. Comparison between completely and traditionally retroperitoneoscopic nephroureterectomy for upper tract urothelial cancer. World J Surg Oncol. 2016;14(1):171. https://doi. org/10.1186/s12957-016-0924-3.

7. Kirkali Z, Chan T, Manoharan M, Algaba F, Busch C, Cheng L, et al. Bladder cancer: epidemiology, staging and grading, and diagnosis. Urology. 2005; 66(6 Suppl 1):4-34. https://doi.org/10.1016/j.urology.2005.07.062.

8. Carneiro BA, Meeks JJ, Kuzel TM, Scaranti M, Abdulkadir SA, Giles FJ. Emerging therapeutic targets in bladder cancer. Cancer Treat Rev. 2015; 41(2):170-8. https://doi.org/10.1016/j.ctrv.2014.11.003.

9. Pouessel D, Bastuji-Garin S, Houede N, Vordos D, Loriot Y, Chevreau C, et al. Adjuvant chemotherapy after radical cystectomy for urothelial bladder cancer: outcome and prognostic factors for survival in a French multicenter, contemporary cohort. Clin Genitourin Cancer. 2017;15(1):e45-52. https://doi. org/10.1016/j.clgc.2016.07.012.

10. Otto W, van Rhijn BW, Breyer J, Bertz S, Eckstein M, Mayr R, et al. Infiltrative lamina propria invasion pattern as an independent predictor for cancer- specific and overall survival of instillation treatment-naive stage $\mathrm{T1}$ highgrade urothelial bladder cancer. Int J Urol. 2018;25(5):442-9. https://doi. org/10.1111/iju.13532.

11. Eckstein $M$, Jung $R$, Weigelt $K$, Sikic D, Stohr R, Geppert C, et al. Piwi-like 1 and -2 protein expression levels are prognostic factors for muscle invasive urothelial bladder cancer patients. Sci Rep. 2018;8(1):17693. https://doi.org/1 0.1038/s41598-018-35637-4.

12. Fransen VDPE, Behrendt MA, Pigot GL, van der Kwast $T H$, van Rhijn BW. Prognostic significance of substage and WHO classification systems in T1 urothelial carcinoma of the bladder. Curr Opin Urol. 2015;25(5):427-35. https://doi.org/10.1097/MOU.0000000000000202.

13. Leissner J, Koeppen C, Wolf HK. Prognostic significance of vascular and perineural invasion in urothelial bladder cancer treated with radical cystectomy. J Urol. 2003;169(3):955-60. https://doi.org/10.1097/01.ju.0000043 639.55877.17.

14. Wang L, Zhou M, Feng C, Gao P, Ding G, Zhou Z, et al. Prognostic value of Ki67 and p63 expressions in bladder cancer patients who underwent radical cystectomy. Int Urol Nephrol. 2016;48(4):495-501. https://doi.org/10.1007/ s11255-015-1197-4.

15. Radkiewicz C, Edgren G, Johansson A, Jahnson S, Haggstrom C, Akre O, et al. Sex differences in urothelial bladder cancer survival. Clin Genitourin Cancer. 2020;18(1):26-34. https://doi.org/10.1016/j.clgc.2019.10.020.

16. Shao Y, Li W, Wang D, Wu B. Prognostic value of preoperative lymphocyterelated systemic inflammatory biomarkers in upper tract urothelial carcinoma patients treated with radical nephroureterectomy: a systematic review and meta-analysis. World J Surg Oncol. 2020;18(1):273. https://doi. org/10.1186/s12957-020-02048-7.

17. Doll KM, Rademaker A, Sosa JA. Practical guide to surgical data sets: surveillance, epidemiology, and end results (SEER) database. JAMA Surg. 2018;153(6):588-9. https://doi.org/10.1001/jamasurg.2018.0501.

18. Al-Husseini MJ, Kunbaz A, Saad AM, Santos JV, Salahia S, lqbal M, et al. Trends in the incidence and mortality of transitional cell carcinoma of the bladder for the last four decades in the USA: a SEER-based analysis. BMC Cancer. 2019;19(1):46. https://doi.org/10.1186/s12885-019-5267-3.

19. Gu JK, Charles LE, Burchfiel CM, Andrew ME, Violanti JM. Cancer incidence among police officers in a U.S. northeast region: 1976-2006. Int J Emerg Ment Health. 2011;13(4):279-89.

20. Nielsen ME, Smith AB, Meyer AM, Kuo TM, Tyree S, Kim WY, et al. Trends in stage-specific incidence rates for urothelial carcinoma of the bladder in the United States: 1988 to 2006. Cancer. 2014;120(1):86-95. https://doi.org/10.1 002/cncr.28397.

21. Abdel-Rahman O. Squamous cell carcinoma of the bladder: a SEER database analysis. Clin Genitourin Cancer. 2017;15(3):e463-8. https://doi.org/10.1016/j. clgc.2016.10.007.

22. Raman JD, Messer J, Sielatycki JA, Hollenbeak CS. Incidence and survival of patients with carcinoma of the ureter and renal pelvis in the USA, 19732005. BJU Int. 2011;107(7):1059-64. https://doi.org/10.1111/j.1464-410X.2010. 09675.x.

23. Homma Y, Kawabe K, Kitamura T, Nishimura $Y$, Shinohara M, Kondo $Y$, et al. Increased incidental detection and reduced mortality in renal cancer--recent retrospective analysis at eight institutions. Int J Urol. 1995;2(2):77-80. https:// doi.org/10.1111/j.1442-2042.1995.tb00428.x.

24. Cumberbatch M, Jubber I, Black PC, Esperto F, Fiqueroa JD, Kamat AM, et al. Epidemiology of bladder cancer: a systematic review and contemporary update of risk factors in 2018. Eur Urol. 2018;74(6):784-95. https://doi.org/1 0.1016/j.eururo.2018.09.001

25. Schulz GB, Grimm T, Buchner A, Jokisch F, Kretschmer A, Stief CG, et al. Bladder cancer stage development, 2004-2014 in Europe compared with the United States: analysis of European Population-based Cancer Registries, the United States SEER Database, and a Large Tertiary Institutional Cohort. Clin Genitourin Cancer. 2020;18(3):162-70. https://doi.org/10.1016/j.clgc.2019.10.008.

26. Jazzar U, Yong S, Klaassen Z, Huo J, Hughes BD, Esparza E, et al. Impact of psychiatric illness on decreased survival in elderly patients with bladder cancer in the United States. Cancer. 2018;124(15):3127-35. https://doi.org/1 0.1002/cncr.31404

27. Tang F, He Z, Lu Z, Wu W, Chen Y, Wei G, et al. Application of nomograms in the prediction of overall survival and cancer-specific survival in patients with T1 high-grade bladder cancer. Exp Ther Med. 2019;18(5):3405-14.

28. Dong F, Shen Y, Gao F, Shi X, Xu T, Wang X, et al. Nomograms to predict individual prognosis of patients with primary small cell carcinoma of the bladder. J Cancer. 2018;9(7):1152-64. https://doi.org/10.7150/jca.23344. 
29. Sung JM, Martin JW, Jefferson FA, Sidhom DA, Piranviseh K, Huang M, et al. Racial and socioeconomic disparities in bladder cancer survival: analysis of the California Cancer Registry. Clin Genitourin Cancer. 2019;17(5):e995-1002. https://doi.org/10.1016/j.clgc.2019.05.008.

30. Weiner AB, Keeter MK, Manjunath A, Meeks JJ. Discrepancies in staging, treatment, and delays to treatment may explain disparities in bladder cancer outcomes: an update from the National Cancer Data Base (20042013). Urol Oncol. 2018;36(5):237-9.

31. Boyd C, Zhang-Salomons JY, Groome PA, Mackillop WJ. Associations between community income and cancer survival in Ontario, Canada, and the United States. J Clin Oncol. 1999;17(7):2244-55. https://doi.org/10.1200/ JCO.1999.17.7.2244.

32. Kong J, Diao X, Diao F, Fan X, Zheng J, Yan D, et al. Causes of death in long-term bladder cancer survivors: a population-based study. Asia Pac $J$ Clin Oncol. 2019;15(5):e167-74. https://doi.org/10.1111/ajco.13156.

33. Underwood WR, Dunn RL, Williams C, Lee CT. Gender and geographic influence on the racial disparity in bladder cancer mortality in the US. J Am Coll Surg. 2006;202(2):284-90. https://doi.org/10.1016/j.jamcollsurg.2 005.09.009.

34. Ishioka J, Saito K, Sakura M, Yokoyama M, Matsuoka Y, Numao N, et al. Development of a nomogram incorporating serum C-reactive protein level to predict overall survival of patients with advanced urothelial carcinoma and its evaluation by decision curve analysis. Br J Cancer. 2012;107(7):10316. https://doi.org/10.1038/bjc.2012.254.

35. Chamie K, Litwin MS, Bassett JC, Daskivich TJ, Lai J, Hanley JM, et al. Recurrence of high-risk bladder cancer: a population-based analysis. Cancer Am Cancer Soc. 2013;119(17):3219-27.

36. Zhang Y, Hong YK, Zhuang DW, He XJ, Lin ME. Bladder cancer survival nomogram: development and validation of a prediction tool, using the SEER and TCGA databases. Medicine. 2019;98(44):e17725.

37. Li X, Cui M, Gu X, Fang D, Li H, Qin S, et al. Pattern and risk factors of local recurrence after nephroureterectomy for upper tract urothelial carcinoma. World J Surg Oncol. 2020;18(1):114. https://doi.org/10.1186/ s12957-020-01877-w.

38. Zhang X, Wang K, Ma J, Zhang Q, Liu C, Cui Y, et al. Total laparoscopic nephroureterectomy for upper urinary tract urothelial carcinoma under a single surgical position. World J Surg Oncol. 2019;17(1):65. https://doi.org/1 0.1186/s12957-019-1601-0.

\section{Publisher's Note}

Springer Nature remains neutral with regard to jurisdictional claims in published maps and institutional affiliations.

Ready to submit your research? Choose BMC and benefit from:

- fast, convenient online submission

- thorough peer review by experienced researchers in your field

- rapid publication on acceptance

- support for research data, including large and complex data types

- gold Open Access which fosters wider collaboration and increased citations

- maximum visibility for your research: over $100 \mathrm{M}$ website views per year

At $\mathrm{BMC}$, research is always in progress.

Learn more biomedcentral.com/submissions 